\title{
Precise measurement of chlorine stable isotopic ratios by thermal ionization mass spectrometry
}

\author{
MASAhiko NUMATA, ${ }^{1} *$ NOBORU NAKAMURA ${ }^{1,2}$ and TOSHITAKA GAMO ${ }^{3}$ \\ ${ }^{1}$ Graduate School of Science and Technology, Kobe University, Kobe 657-8501, Japan \\ ${ }^{2}$ Department of Earth and Planetary Science, Faculty of Science, Kobe University, Kobe 657-8501, Japan \\ ${ }^{3}$ Graduate School of Science, Hokkaido University, Sapporo 060-0810, Japan
}

(Received August 7, 2000; Accepted January 15, 2001)

\begin{abstract}
An improved method for chlorine isotopic analysis by thermal ionization mass spectrometry of $\mathrm{Cs}_{2} \mathrm{Cl}^{+}$ has been investigated for precise measurement of ${ }^{37} \mathrm{Cl} /{ }^{35} \mathrm{Cl}$ isotopic ratios for small amount of samples. Chlorine in organic and inorganic samples was recovered as $\mathrm{AgCl}$ and converted to $\mathrm{CsCl}$ with metallic $\mathrm{Mg}$ and Cs-form ion exchange resin. The $\mathrm{CsCl}$ (containing $2 \mu \mathrm{g}$ of $\mathrm{Cl}$ ) was loaded on a Ta filament together with graphite powder. The ${ }^{37} \mathrm{Cl} /{ }^{35} \mathrm{Cl}$ ratio measurement was carried out using $\mathrm{Cs}_{2} \mathrm{Cl}^{+}$ions with multi Faraday cup (static mode) for 80-100 min each single run. Replicate analysis of ocean water and laboratory standard ( $\mathrm{CsCl}$ reagent) yield the in-run precision of $0.1-0.2 \%$ ( $\left(2 \sigma_{\mathrm{m}}\right)$ for $300-400$ ratios and external precision of $0.1-0.2 \% \circ\left(1 \sigma_{\mathrm{SD}}\right)$. This method has been tested on a variety of chemical reagents including metal chlorides, hydrochloric acid and chlorinated organic solvents. It was found that the artificial chlorine compound show large variations of ${ }^{37} \mathrm{Cl} /{ }^{35} \mathrm{Cl}$ ratio (total ranges from -5 to $+3 \%$ relative to standard mean ocean chloride) depending upon manufacturing processes. We suggest that the high sensitivity and precision technique established in this work would allow us to detect small isotopic variations of chlorine in small amounts of natural samples such as terrestrial materials (minerals/rocks, sediments, groundwater, etc, as well as environmental materials), meteorites and other planetary materials.
\end{abstract}

\section{INTRODUCTION}

Variations in the isotopic compositions of chlorine $\left({ }^{37} \mathrm{Cl} /{ }^{35} \mathrm{Cl}\right)$ are useful diagnostic tool for processes associated with important geochemical reactions in the atmosphere, surface fluids and the lithosphere (Hoefs, 1997). The chlorine isotopes are chiefly fractionated by phase change of $\mathrm{Cl}$ bearing materials, e.g., evaporites crystallized from brine (Vengosh et al., 1989; Eggenkamp et al., 1995; Liu et al., 1997; Lyons et al., 1999), reaction between hydrous silicate minerals and aqueous phase (Eastoe and Guilbert, 1992; Magenheim et al., 1995; Ransom et al., 1995), and volatilization of $\mathrm{HCl}$ from acidic aerosols (Volpe and Spivack, 1994; Volpe et al., 1998; Lyons et al., 1999). Although the isotopic abundances are generally utilized as conservative tracers in hydrology (Phillips, 1995), not only mixing of waters from different sources (Kaufmann et al., 1993) but also difference of diffusion rate between ${ }^{35} \mathrm{Cl}^{-}$ and ${ }^{37} \mathrm{Cl}^{-}$(Desaulniers et al., 1986; Eggenkamp et al., 1994), and ion filtration effect in clay layers (Phillips and Bentley, 1987) cause variation of $\mathrm{Cl}$ isotopic ratio in groundwater. The studies of nonconservative behavior of $\mathrm{Cl}$ have potential for constraining the distribution and chemical evolution of volatile elements on the Earth (Magenheim et al., 1995; Eggenkamp and Koster van Groos, 1997; Markl et al., 1997).

Chlorinated organic compounds that are produced for industrial use or formed as by-product,

*Present address: National Institute of Advanced Industrial Science and Technology, 1-1 Higashi, Tsukuba, Ibaraki 305-8565, Japan

*Corresponding author (e-mail: numata@shidahara1.planet.sci.kobe-u.ac.jp) 
have resulted in many environmental problems. Tanaka and Rye (1991) reported large variations of $\mathrm{Cl}$ isotopic compositions in some volatile organic compounds, and suggested that it could be used to quantify the flux of stratospheric $\mathrm{Cl}$ derived from artificial chlorinated compounds. Isotopic compositions of chlorinated organic solvents would also be useful to distinguish sources of groundwater contaminants (van Warmerdam et al., 1995) and to evaluate their degradation in aquifers (Sturchio et al., 1998).

Several techniques, involving electron impact ionization mass spectrometry (Boyd et al., 1955; Hoering and Parker, 1961; Taylor and Grimsrud, 1969; Kaufmann et al., 1984; Long et al., 1993), negative thermal ionization mass spectrometry (Shields et al., 1962; Vengosh et al., 1989) and fast atom bombardment-mass spectrometry (Wastaway et al., 1998) have been developed to determine the isotopic composition of $\mathrm{Cl}$. However, the study of $\mathrm{Cl}$ isotopes was limited by lack of precision or sensitivity. Sensitivity of isotopic analysis is much important for the samples like meteorites and environmental pollutants because their size and concentration of $\mathrm{Cl}$ are sometimes limited.

Thermal ionization mass spectroscopy (TIMS) of $\mathrm{Cs}_{2} \mathrm{Cl}^{+}$has small mass dependent fractionation, high sensitivity and low filament blank (Xiao and Zhang, 1992; Magenheim et al., 1994; Xiao et al., 1995; Rosenbaum et al., 2000). It has been used successfully in the investigation of brines (Liu et al., 1997), aerosols (Magenheim et al., 1994; Volpe and Spivack, 1994; Volpe et al., 1998), rocks (Magenheim et al., 1994; Magenheim et al., 1995; Boudreau et al., 1997; Banks et al., 2000), and subduction-zone pore waters (Ransom et al., 1995) in magnetic scanning (peak jumping) mode.

In this work, in order to develop an improved method of the $\mathrm{Cl}$ isotopic analysis using TIMS which is applicable to tiny planetary materials, repeated analysis of ocean water and a reagent standard have been carried out in different conditions. We have established a high sensitivity, precision method which enable us to analyze $\mathrm{Cl}$ isotopes with precision of $\sim 0.1 \%$ ofor $2 \mu \mathrm{g}$-size $\mathrm{Cl}$, demonstrated detailed methods and presented analytical results for ocean water and Cl-bearing commercial inorganic and organic reagents in this work.

\section{Experimental Procedures}

\section{Seawater samples and reagents}

Seawater samples from the Pacific Ocean were taken during the KH-98-1 expedition by research vessel Hakuho-maru of the Ocean Research Institute (University of Tokyo). In addition, in order to find possible variation of $\mathrm{Cl}$ isotopic composition caused by human activities, coast water from Setouchi area (Setonaikai) was analyzed. The seawater samples were stored at $-20^{\circ} \mathrm{C}$ until use, and filtered with a $0.45 \mu \mathrm{m}$ membrane filter before pretreatment for isotopic measurement.

High purity $\mathrm{CsCl}$ (99.999\% purity, Aldrich) and commercial grade $\mathrm{CsCl}$ (>99\%, Nacalai tesque; $>99 \%$, Wako Pure Chemical Industries) were stored as $9.5 \mathrm{~g} / \mathrm{l}(2 \mathrm{~g}-\mathrm{Cl} / \mathrm{l})$ solutions.

$\mathrm{NaCl}$ (99.99\%, Matsunaga Chemical), $\mathrm{HCl}$ (reagent grade hydrochloric acid, Wako Pure Chemical Industries; High-purity $\mathrm{HCl}$ gas, Sumitomo Seika Chemicals), KCl (>99.5\%, Wako Pure Chemical Industries), tetrachloromethane (>99\%, Nacalai tesque), 1,1,1-trichloroethane (97\%, Wako Pure Chemical Industries), 1,1dichloroethene (99\%, GL Sciences), trichloroethene $(>99.5 \%$, Wako Pure Chemical Industries), and tetrachloroethene (>99\%, Wako Pure Chemical Industries) were used for $\mathrm{Cl}$ isotopic measurements. Other chemicals were analytical or reagent grades.

\section{Ion chromatography}

Analysis of chloride ion and other anions was performed on a Hitachi ion chromatograph L-7000. A $20 \mu$ l volume of the sample was injected into the mobile phase. Separations were performed with a Hitachi 2740 guard column and a Hitachi 2740 analytical column with a mixed eluent of 2.3 $\mathrm{mM}$ phthalic acid, and $2.5 \mathrm{mM}$ 2-amino-2hydroxymethyl-1,3-propanediol. A Shodex IC 
YK-421 guard column and a Shodex IC YK-421 analytical column with a mixed eluent of $1.0 \mathrm{mM}$ 2,6-pyridinedicarboxylic acid, 5.0 $\mathrm{mM} \mathrm{L-tartaric}$ acid, and $24 \mathrm{mM}$ boric acid were used for analysis of alkali metal and alkali earth ions.

\section{Preparation of $\mathrm{CsCl}$}

Chloride ion in aqueous solution (seawater, dissolved inorganic reagents and decomposition products of organic compounds) was isolated as $\mathrm{AgCl}$ and converted into $\mathrm{CsCl}$ by the method of

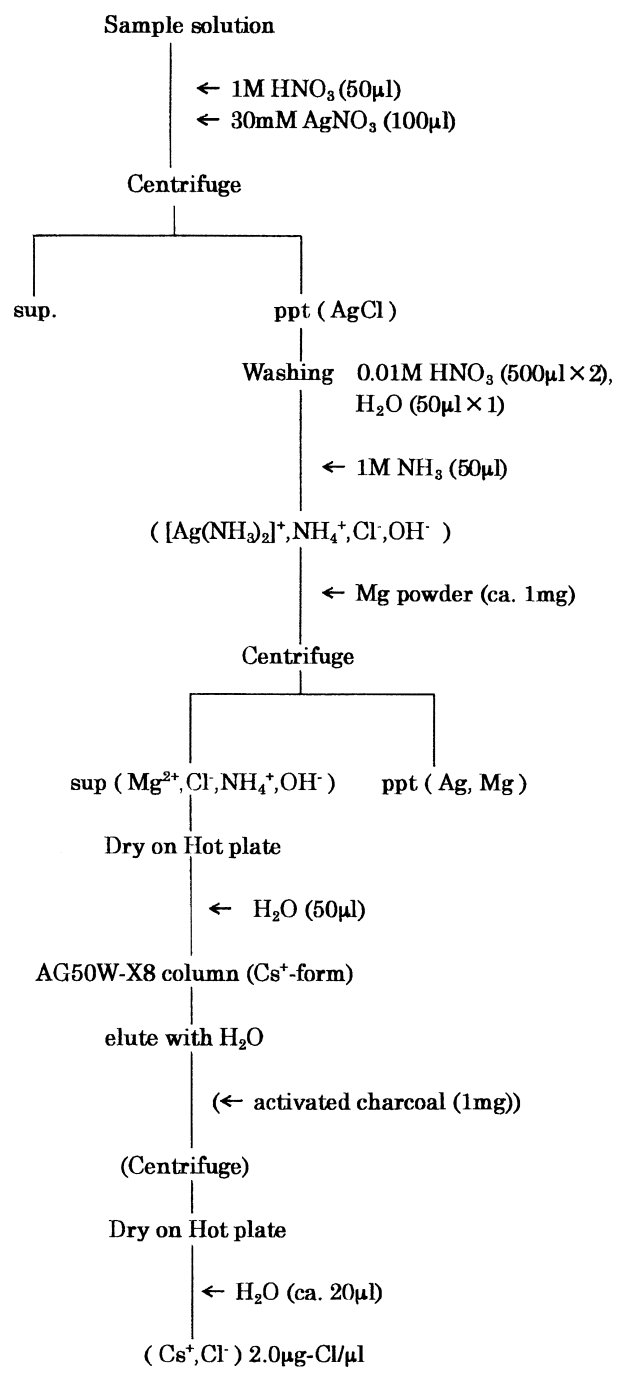

Fig. 1. Procedures of $C s C l$ preparation from seawater, inorganic reagents and chloride ion recovered from organic compounds.
Hoering and Parker (1961) and Magenheim et al. (1994) with some modifications (Fig. 1). For analysis of chlorinated organic compounds, covalently bonded $\mathrm{Cl}$ atoms were liberated as $\mathrm{Cl}^{-}$ with sodium biphenyl reagent by the method of Liggett (1954) with some modifications (Fig. 2).

The chlorinated organic compounds (1.2 to 1.6 $\mathrm{mg}$ ) were added to $2 \mathrm{ml}$ of toluene in test tubes with screw stoppers. The reductive dechlorination reaction was performed under nitrogen atmosphere in a polyethylene bag to prevent degradation of the sodium biphenyl reagent with moisture and oxygen. The air in the bag was replaced with nitrogen gas, and $0.2 \mathrm{ml}$ of sodium biphenyl reagent (1 M solution in dimethoxyethane, Dojindo Laboratory) was added to the each tube. After 30 min, $0.5 \mathrm{ml}$ of water was added and shaken to

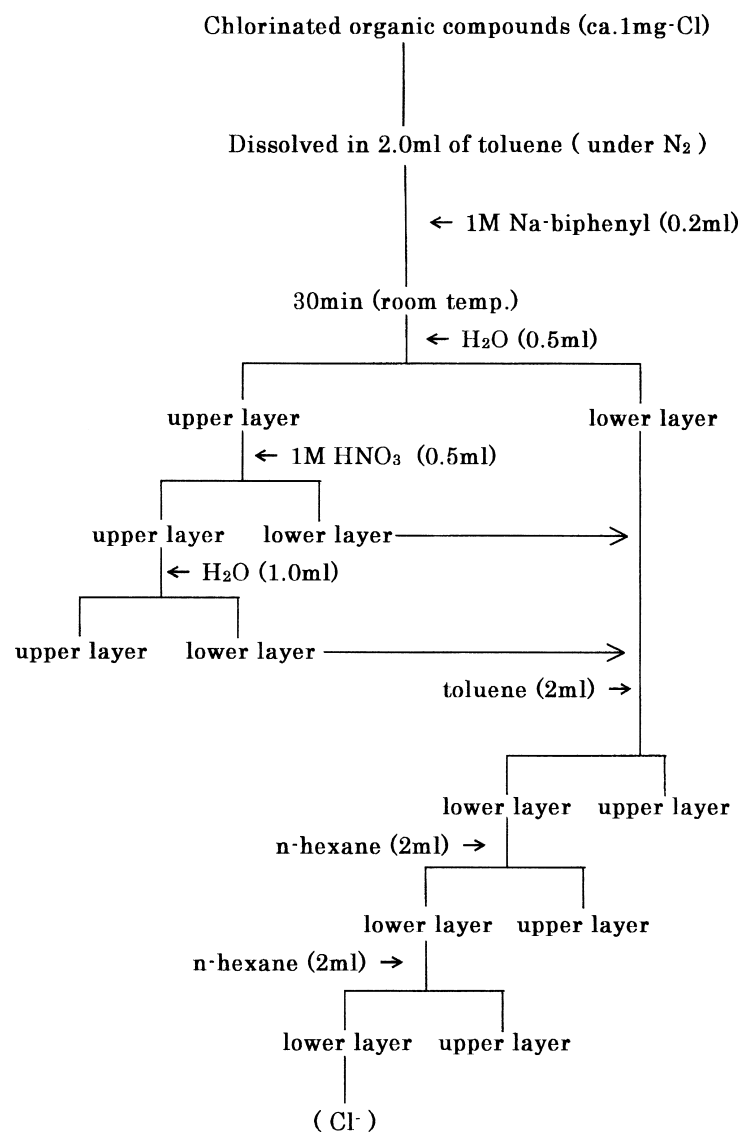

Fig. 2. Procedures of reductive dechlorination of chlorinated organic compounds with Na-biphenyl reagent. 
extract $\mathrm{Cl}^{-}$and to destroy the excess reagent. After separation of the lower aqueous layer, residual $\mathrm{Cl}^{-}$was extracted with $0.5 \mathrm{ml}$ of $1 \mathrm{M} \mathrm{HNO}_{3}$ and 1 $\mathrm{ml}$ of $\mathrm{H}_{2} \mathrm{O}$ respectively. The extracted fractions were combined and washed with $2 \mathrm{ml}$ of toluene and n-hexane to remove organic compounds. Finally, the water layer was diluted to $10 \mathrm{ml}$ with $\mathrm{H}_{2} \mathrm{O}$.

Sample solutions that contain $50 \mu \mathrm{g}$ of $\mathrm{Cl}^{-}$were put into polypropylene centrifuge tubes. Fifty microliters of $1 \mathrm{M} \mathrm{HNO}_{3}$ and $100 \mu \mathrm{l}$ of $30 \mathrm{mM}$ $\mathrm{AgNO}_{3}$ solution was added to each tube, and then kept for 2 hours at room temperature in the dark. The solution was centrifuged at 15,000 rpm for 5 min, and the supernatant was discarded. Precipitation of $\mathrm{AgCl}$ was washed with $500 \mu \mathrm{l}$ of $0.01 \mathrm{M}$ $\mathrm{HNO}_{3}$ twice and $50 \mu \mathrm{l}$ of $\mathrm{H}_{2} \mathrm{O}$ once by centrifugation, and then $50 \mu \mathrm{l}$ of $1 \mathrm{M} \mathrm{NH}_{3}$ was added to dissolve the $\mathrm{AgCl}$. In order to remove $\mathrm{Ag}$ ion, $c a$. $1 \mathrm{mg}$ of $\mathrm{Mg}$ powder was added to the solution. After one-hour reaction, the solution was centrifuged and the supernatant was recovered. The precipitation was washed with $50 \mu$ l of water twice. All supernatant fractions were combined and evaporated to dryness on hot plate $\left(120^{\circ} \mathrm{C}\right)$. The residue $\left(\mathrm{NH}_{4} \mathrm{Cl}+\mathrm{MgCl}_{2}\right)$ was dissolved in $50 \mu \mathrm{l}$ of water and loaded on a column (i.d. $2 \mathrm{~mm}$ ) that contained $0.1 \mathrm{ml}$ of Cs-form cation exchange resin (DOWEX 50W $\times 8,200-400 \mathrm{mesh}$ ). The column was washed with $170 \mu \mathrm{l}$ of water. For the isotopic analysis of organic compounds, organic contaminants that would prevent ionization were removed from the eluent by addition of activated charcoal powder (1 mg, GL Sciences GX-60). The charcoal powder was washed with $\mathrm{H}_{2} \mathrm{O}$ to remove $\mathrm{Cl}^{-}$ and then added to the eluent as suspension, after $30 \mathrm{~min}$ it was removed from the eluent by centrifugation. The concentration of the $\mathrm{Cl}^{-}$in the eluent was measured by ion chromatography, and the eluent was evaporated to dryness on hot plate. The amount of $\mathrm{Cl}^{-}$was calculated from the $\mathrm{Cl}^{-}$ concentration and volume of the eluent, and then water was added to the solid residue $(\mathrm{CsCl})$ to form a $2 \mathrm{~g}-\mathrm{Cl} / \mathrm{l}$ solution.

Seawater samples were treated by a different procedure as follows. Seawater (ca. $25 \mu \mathrm{l}$, con- taining $0.5 \mathrm{mg}$ of $\mathrm{Cl}$ ) was passed through $\mathrm{Ba}$-form cation exchange resin $(50 \mathrm{~W} \times 8,0.2 \mathrm{ml}$ in a column), and Cs-form cation exchange resin $(50 \mathrm{~W} \times$ $8,0.1 \mathrm{ml}$ in a column). The eluent $(c a .250 \mu \mathrm{l})$ was recovered, and concentrations of $\mathrm{Cs}^{+}$and $\mathrm{Cl}^{-}$ were measured by ion chromatography.

\section{Mass spectrometry}

Measurements of isotopic composition were performed using a Finnigan MAT Model 262 thermal ionization mass spectrometer. This instrument has an equivalent radius of $64 \mathrm{~cm}$ and a $90^{\circ}$ geometry. The instrument has five Faraday cup detectors, coupled to $10^{11} \Omega$ resistors, a secondary electron multiplier, and a retarding potential quadrupole system. Flat undegassed Ta ribbons (purity: $99.95 \% ; 0.025 \times 1.5 \mathrm{~mm}$, Nilaco) were used for single filament mode measurements (Table 1).

The mass spectrometric procedure was the modified method of Xiao and Zhang (1992), Magenheim et al. (1994), and Xiao et al. (1995). Two micrograms of chlorine as $\mathrm{CsCl}$ aqueous solution $(9.5 \mathrm{~g}-\mathrm{CsCl} / \mathrm{l} \times 1.0 \mu \mathrm{l})$ and $c a .50 \mu \mathrm{g}$ of graphite powder as a slurry in $80 \%$ ethanol were mixed on a polytetrafluoroethylene sheet. The mixture was loaded on the center of the filament and then dried with a filament current of $1.5 \mathrm{~A}$. The filaments were loaded in the ion source of the mass spectrometer and the analysis was started when the pressure in the ion source reached less than $10^{-5} \mathrm{~Pa}$. The filament current was automatically increased to $1.2 \mathrm{~A}$ in $10 \mathrm{~min}$, and then increased manually to detect and focus $\mathrm{Cs}_{2}{ }^{35} \mathrm{Cl}^{+}$ion

Table 1. Conditions of mass spectrometry

\begin{tabular}{ll}
\hline Filament & undegassed Ta \\
Sample loading & \\
$\quad$ Amount of chloride ion & $2 \mu \mathrm{g}$ \\
$\mathrm{pH}$ & $5-6$ \\
$\quad \mathrm{Cs}^{+}: \mathrm{Cl}^{-}$(molar ratio) & $1: 1$ \\
$\quad$ Drying (filament current) & $1.5 \mathrm{~A}, 0.5 \mathrm{~min}$ \\
Filament current & $0 \rightarrow 1.2 \mathrm{~A}(0.12 \mathrm{~A} / \mathrm{min})$ \\
$\quad$ Preheat & $1.42-1.48 \mathrm{~A}$ \\
$\quad$ Measurement & $2-5 \times 10^{-13} \mathrm{~A}$ \\
\hline
\end{tabular}


beam. The intensity of $\mathrm{Cs}_{2}{ }^{35} \mathrm{Cl}^{+}$ion current was adjusted to (2-3) $\times 10^{-13} \mathrm{~A}$ by the filament current, which was typically $1.4-1.5 \mathrm{~A}$. In order to detect the target ions $\left(\mathrm{Cs}_{2}{ }^{35} \mathrm{Cl}^{+}: \mathrm{m} / \mathrm{z}=301\right.$ and $\left.\mathrm{Cs}_{2}{ }^{37} \mathrm{Cl}^{+}: \mathrm{m} / \mathrm{z}=303\right)$, the accelerating voltage was set to $8 \mathrm{kV}$.

Data were acquired in static (multi-Faraday cup) mode for less than $100 \mathrm{~min}$. Typically 400 to 500 ratios were collected in blocks from 20 to 25 .

\section{RESULTS AND DISCUSSION}

\section{Seawater}

The results of $\mathrm{Cl}$ isotopic measurements of seawater $\left(8^{\circ} 39.5^{\prime} \mathrm{N}, 153^{\circ} 56.6^{\prime} \mathrm{E}\right)$ chloride are shown in Table 2 and Fig. 3. The results of runs 1 to 11 were obtained for chloride recovered by treatment with $\mathrm{Ba}$ and $\mathrm{Cs}$-form ion exchange resin, and the results of runs 12 to 25 were obtained for those recovered as $\mathrm{AgCl}$. The mean ${ }^{37} \mathrm{Cl} /{ }^{35} \mathrm{Cl}$ ratios obtained by latter method appear to be lower, but the difference was not significant. The recovery yield of $\mathrm{Cl}$ as $\mathrm{CsCl}$ ranged from 79 to $94 \%$

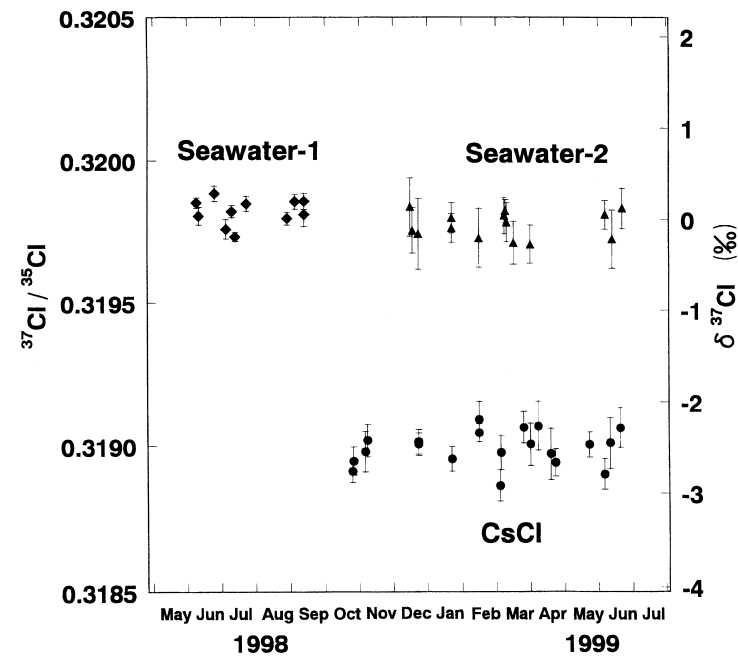

Fig. 3. Chlorine isotopic compositions of seawater and a CsCl reagent for the period between June 1998 and July 1999. The seawater was taken from the Pacific Ocean (8³9.5' N, $153^{\circ} 56.6^{\prime}$ E) in March 1998 (Seawater-1: The seawater was treated with Ba-form resin and $C s$-form resin; Seawater-2: The seawater was treated with $\mathrm{AgNO}_{3}, \mathrm{Mg}$, and Cs-form resin). The commercial grade (purity: >99\%) CsCl reagent was obtained from Nacalai tesque, Kyoto. Error bars represent $2 \sigma_{m}\left(\sigma_{m}\right.$ : internal standard error $)$.

Table 2. Measured Cl isotopic compositions of the seawater sample $\left(8^{\circ} 39.5^{\prime} \mathrm{N}, 153^{\circ} 56.6^{\prime} \mathrm{E}\right.$, depth: $\left.0 \mathrm{~m}\right)$

\begin{tabular}{|c|c|c|c|}
\hline Run & $\begin{array}{l}\text { Ion exchange }{ }^{(a)} \\
{ }^{37} \mathrm{Cl}^{\beta 5} \mathrm{Cl}^{(\mathrm{c})}\end{array}$ & Run & $\begin{array}{c}\text { Recovered as } \mathrm{AgCl}^{(\mathrm{b})} \\
{ }^{37} \mathrm{Cl}^{\beta 5} \mathrm{Cl}^{(\mathrm{c})}\end{array}$ \\
\hline 1 & $0.319852 \pm 0.000018$ & 12 & $0.319838 \pm 0.000102$ \\
\hline 2 & $0.319806 \pm 0.000031$ & 13 & $0.319756 \pm 0.000080$ \\
\hline 3 & $0.319885 \pm 0.000027$ & 14 & $0.319744 \pm 0.000123$ \\
\hline 4 & $0.319760 \pm 0.000033$ & 15 & $0.319799 \pm 0.000053$ \\
\hline 5 & $0.319821 \pm 0.000021$ & 16 & $0.319764 \pm 0.000050$ \\
\hline 6 & $0.319734 \pm 0.000015$ & 17 & $0.319729 \pm 0.000103$ \\
\hline 7 & $0.319849 \pm 0.000027$ & 18 & $0.319807 \pm 0.000064$ \\
\hline 8 & $0.319797 \pm 0.000022$ & 19 & $0.319823 \pm 0.000041$ \\
\hline 9 & $0.319856 \pm 0.000026$ & 20 & $0.319784 \pm 0.000068$ \\
\hline 10 & $0.319811 \pm 0.000041$ & 21 & $0.319712 \pm 0.000075$ \\
\hline 11 & $0.319857 \pm 0.000029$ & 22 & $0.319707 \pm 0.000067$ \\
\hline- & - & 23 & $0.319811 \pm 0.000050$ \\
\hline - & - & 24 & $0.319725 \pm 0.000102$ \\
\hline - & - & 25 & $0.319834 \pm 0.000070$ \\
\hline average & $0.319821 \pm 0.000045^{(\mathrm{d})}$ & average & $0.319774 \pm 0.000046^{(\mathrm{d})}$ \\
\hline
\end{tabular}

${ }^{(a)}$ Seawater was treated with Ba-resin and Cs-resin.

${ }^{(b)}$ Seawater was treated with $\mathrm{AgNO}_{3}, \mathrm{Mg}$ and $\mathrm{Cs}$-resin.

${ }^{(c)}$ Error for the individual runs is $2 \sigma_{m}\left(\sigma_{m}\right.$ : standard error).

${ }^{(d)}$ Error for the average value is $1 \sigma_{S D}\left(\sigma_{S D}\right.$ : standard deviation). 
Table 3. Measured Cl isotopic compositions of seawater samples

\begin{tabular}{lrcccc}
\hline \multicolumn{1}{l}{ Location } & Depth (m) & Salinity $(\% \circ)$ & Temp. $\left({ }^{\circ} \mathrm{C}\right)$ & Sampling date & ${ }^{37} \mathrm{Cl}^{35} \mathrm{Cl}^{*}$ \\
\hline Pacific Ocean & & & & & \\
$8^{\circ} 39.5^{\prime} \mathrm{N}, 153^{\circ} 56.6^{\prime} \mathrm{E}$ & 0 & 34.873 & 28.0 & $03 / 04 / 1998$ & $0.319820 \pm 0.000037(n=7)$ \\
$12^{\circ} 06.9^{\prime} \mathrm{N}, 138^{\circ} 52.3^{\prime} \mathrm{E}$ & 0 & 34.387 & 26.4 & $03 / 08 / 1998$ & $0.319894 \pm 0.000171(n=5)$ \\
$12^{\circ} 58.4^{\prime} \mathrm{N}, 143^{\circ} 43.7^{\prime} \mathrm{E}$ & 0 & 34.397 & - & $03 / 10 / 1998$ & $0.319847 \pm 0.000041(n=3)$ \\
$18^{\circ} 12.9^{\prime} \mathrm{N}, 144^{\circ} 42.0^{\prime} \mathrm{E}$ & 0 & 34.843 & 27.0 & $03 / 11 / 1998$ & $0.319829 \pm 0.000079(n=4)$ \\
$18^{\circ} 12.7^{\prime} \mathrm{N}, 144^{\circ} 42.2^{\prime} \mathrm{E}$ & 992 & 34.470 & 4.1 & $03 / 11 / 1998$ & $0.319870 \pm 0.000087(n=4)$ \\
$18^{\circ} 12.7^{\prime} \mathrm{N}, 144^{\circ} 42.2^{\prime} \mathrm{E}$ & 3235 & 34.667 & 1.7 & $03 / 11 / 1998$ & $0.319883 \pm 0.000091(n=5)$ \\
$18^{\circ} 12.7^{\prime} \mathrm{N}, 144^{\circ} 42.2^{\prime} \mathrm{E}$ & 3725 & 34.669 & 1.7 & $03 / 11 / 1998$ & $0.319856 \pm 0.000079(n=6)$ \\
$26^{\circ} 30.2^{\prime} \mathrm{N}, 142^{\circ} 39.4^{\prime} \mathrm{E}$ & 0 & 34.947 & 22.9 & $03 / 13 / 1998$ & $0.319853 \pm 0.000117(n=4)$ \\
Setonaikai & & & & & \\
$34^{\circ} 38.3^{\prime} \mathrm{N}, 135^{\circ} 07.0^{\prime} \mathrm{E}$ & 0 & 31.6 & - & $02 / 08 / 1998$ & $0.319849 \pm 0.0000093(n=4)$ \\
\hline
\end{tabular}

*Error: $2 \sigma_{m}\left(\sigma_{m}\right.$ : external standard error $)$.

Period of the analysis: June 1998-July 1998.

(average: $88 \%$ ) by the $\mathrm{AgCl}$-precipitation procedure.

The ion current intensities for runs 1 to 11 were higher $\left(4-7 \times 10^{-13} \mathrm{~A}\right)$ than values of runs 12 to $25\left(2-4 \times 10^{-13} \mathrm{~A}\right)$. Although the internal errors $\left(2 \sigma_{\mathrm{m}}\right.$ : standard error of the mean of individual ratios in each run) of runs 12 to 25 were larger than errors of runs 1 to 11 by difference of ion current intensity, there was no difference in external reproducibility $\left(1 \sigma_{\mathrm{SD}}\right.$ : standard deviation of the mean of individual runs) between both pretreatment procedures. The average value (0.319794: run 1-25) was used as standard (standard mean ocean chloride: SMOC (Long et al., 1993), $\delta^{37} \mathrm{Cl}=0 \%$ ) in the following results.

Nine seawater samples from different locations were repeatedly analyzed (Table 3 ). Those samples were treated with $\mathrm{Ba}$-form resin and Cs-form resin before isotopic measurement. The results revealed the isotopic composition of $\mathrm{Cl}$ in seawater is homogeneous as reported previously (Hoering and Parker, 1961; Kaufmann et al., 1984). Hydrothermal activity was found near one of sampling point in the Pacific Ocean $\left(18^{\circ} 12.7^{\prime} \mathrm{N}, 144^{\circ} 42.2^{\prime}\right.$ $\mathrm{E}$; depth $992 \mathrm{~m}$ : minimum salinity layer; depth $3235 \mathrm{~m}$ : center of plume from hydrothermal vent; depth $3725 \mathrm{~m}$ : just above seafloor). Because the samples were not directly collected from hydro- thermal vent, hydrothermal fluid would be highly diluted with seawater. Even if isotopic composition of chloride in hydrothermal fluid was different from seawater, the influence on $\mathrm{Cl}$ isotopic composition in the samples might be negligible. A sample from the In-land Sea (Setonaikai) must be affected by industrial and municipal discharge, but no difference of $\delta^{37} \mathrm{Cl}$ was observed.

\section{$\mathrm{CsCl}$ reagents}

Because NIST SRM $975(\mathrm{NaCl})$ is not available now, there is no international standard for $\mathrm{Cl}$ stable isotopic composition. Although $\mathrm{Cl}$ in seawater is isotopically homogeneous with variations less than the analytical precision, it is possible that the analytical methods could be improved to detect these variations (Xiao et al., 1995). In the case of mass spectrometry of $\mathrm{CH}_{3} \mathrm{Cl}$, reference $\mathrm{CH}_{3} \mathrm{Cl}$ gas is introduced into the spectrometer, and ion beams are measured alternately in the sample and the reference for precise relative measurement (Long et al., 1993; Musashi et al., 1998). In order to compare precision and accuracy between laboratories and to check dayto-day reproducibility in a laboratory by thermal ionization mass spectrometry of $\mathrm{Cs}_{2} \mathrm{Cl}^{+}, \mathrm{CsCl}$ reagent would be suitable as a laboratory reference standard. 
Table 4. Measured Cl isotopic compositions of the $\mathrm{CsCl}$ reagent (Nacalai tesque, $>99 \%$ )

\begin{tabular}{ccc}
\hline Run & \multicolumn{1}{c}{${ }^{37} \mathrm{Cl}{ }^{\beta 5} \mathrm{Cl}$} & $\delta^{37} \mathrm{Cl}(\%)$ \\
\hline Directly loaded ${ }^{(\mathrm{a})}$ & \\
1 & $0.318913 \pm 0.000039$ & $-2.76 \pm 0.12$ \\
2 & $0.318948 \pm 0.000049$ & $-2.65 \pm 0.15$ \\
3 & $0.318981 \pm 0.000071$ & $-2.54 \pm 0.22$ \\
4 & $0.319020 \pm 0.000057$ & $-2.42 \pm 0.18$ \\
5 & $0.319015 \pm 0.000044$ & $-2.44 \pm 0.14$ \\
6 & $0.319007 \pm 0.000040$ & $-2.46 \pm 0.13$ \\
7 & $0.318955 \pm 0.000043$ & $-2.62 \pm 0.13$ \\
8 & $0.319047 \pm 0.000033$ & $-2.33 \pm 0.10$ \\
9 & $0.319096 \pm 0.000061$ & $-2.18 \pm 0.19$ \\
10 & $0.318862 \pm 0.000054$ & $-2.91 \pm 0.17$ \\
11 & $0.318977 \pm 0.000060$ & $-2.55 \pm 0.19$ \\
12 & $0.319067 \pm 0.000057$ & $-2.27 \pm 0.18$ \\
13 & $0.319007 \pm 0.000075$ & $-2.46 \pm 0.24$ \\
14 & $0.319072 \pm 0.000086$ & $-2.26 \pm 0.27$ \\
15 & $0.318973 \pm 0.000090$ & $-2.57 \pm 0.28$ \\
16 & $0.318943 \pm 0.000048$ & $-2.66 \pm 0.15$ \\
17 & $0.319005 \pm 0.000044$ & $-2.47 \pm 0.14$ \\
18 & $0.318902 \pm 0.000053$ & $-2.79 \pm 0.17$ \\
19 & $0.319012 \pm 0.000090$ & $-2.45 \pm 0.28$ \\
20 & $0.319065 \pm 0.000070$ & $-2.28 \pm 0.22$ \\
& & \\
average & $0.318993 \pm 0.000061\left(1 \sigma_{\mathrm{SD}}\right)$ & $-2.49 \pm 0.21\left(1 \sigma_{\mathrm{SD}}\right)$ \\
& & \\
Recovered $\mathrm{Cl}^{(\mathrm{b})}$ & & $-2.81 \pm 0.12$ \\
1 & $0.318896 \pm 0.000040$ & $-2.48 \pm 0.13$ \\
2 & $0.319001 \pm 0.000041$ & $-2.26 \pm 0.17$ \\
3 & $0.319071 \pm 0.000055$ & $-2.58 \pm 0.14$ \\
4 & $0.318851 \pm 0.000046$ & \\
5 & $0.319030 \pm 0.000047$ & \\
& & \\
average & $0.318970 \pm 0.000093\left(1 \sigma_{\mathrm{SD}}\right)$ & \\
\hline
\end{tabular}

Error for the individual runs is $2 \sigma_{m}\left(\sigma_{m}\right.$ : standard error).

${ }^{(a)} \mathrm{CsCl}$ reagent was directly loaded on the filaments.

${ }^{(b)} \mathrm{Cl}^{-}$was recovered from $\mathrm{CsCl}$ as $\mathrm{AgCl}$, and converted to $\mathrm{CsCl}$.

In order to establish a laboratory standard, three lots of commercial $\mathrm{CsCl}$ reagents were analyzed (Tables 4 and 5). We noted that mass spectrometric runs of a commercial grade reagent (Nacalai tesque) were most successful in obtaining stable isotopic ratios over an extended time period (Fig. 3). On the other hand, ion currents from high purity $\mathrm{CsCl}$ (Aldrich, 99.999\%) analyses were occasionally unstable and hence some data which are not given in Table 5 were of poor quality. The reason for the unstable runs of high purity $\mathrm{CsCl}$ is not clear. Therefore, we tentatively concluded that the Nacalai reagent was most safely
Table 5. Measured $\delta^{37} \mathrm{Cl}$ values of the CsCl reagents

\begin{tabular}{ccc}
\hline Run & $\begin{array}{c}\text { Aldrich }(99.999 \%) \\
\delta^{37} \mathrm{Cl}(\%)\end{array}$ & $\begin{array}{c}\text { Wako }(>99 \%) \\
\delta^{37} \mathrm{Cl}(\% \circ)\end{array}$ \\
\hline 1 & $-0.74 \pm 0.22$ & $0.36 \pm 0.15$ \\
2 & $-0.68 \pm 0.41$ & $0.15 \pm 0.12$ \\
3 & $-0.81 \pm 0.14$ & $0.00 \pm 0.14$ \\
4 & $-1.00 \pm 0.15$ & $-0.06 \pm 0.15$ \\
5 & $-0.80 \pm 0.22$ & \\
6 & $-0.66 \pm 0.14$ & \\
7 & $-0.61 \pm 0.43$ & \\
8 & $-0.96 \pm 0.17$ & \\
9 & $-0.96 \pm 0.23$ & \\
& & \\
average & $-0.80 \pm 0.14\left(1 \sigma_{\mathrm{SD}}\right)$ & $0.11 \pm 0.19\left(1 \sigma_{\mathrm{SD}}\right)$ \\
\hline
\end{tabular}

Error for the individual runs is $2 \sigma_{m}\left(\sigma_{m}\right.$ : standard error). $\mathrm{CsCl}$ was directly loaded on the filaments with graphite.

employed as a laboratory standard.

Xiao et al. have reported that the $\mathrm{pH}$ of loading solution affected on efficiency and stability of $\mathrm{Cs}_{2} \mathrm{Cl}^{+}$beam and that the optimum beam was obtained at $\mathrm{pH}=2-5$ (Xiao and Zhang, 1992). The $\mathrm{pH}$ values of $\mathrm{CsCl}$ solutions $(56.4 \mathrm{mM})$ analyzed in this work were 5.7-6.1, which were slightly higher than these of Xiao and Zhang (1992).

\section{Inorganic compounds}

Isotopic composition of $\mathrm{Cl}$ recovered as $\mathrm{AgCl}$ from a $\mathrm{CsCl}$ reagent was measured to check isotopic fractionation by the procedure (Table 4). A significant difference was not observed between the composition obtained by this treatment and that of directly loaded $\mathrm{CsCl}$ reagent. The recovery yield of $\mathrm{Cl}$ ranged from 89 to $96 \%$ (average: 92\%).

Four kinds of inorganic chlorine compounds were used for $\mathrm{Cl}$ isotopic measurement. Chloride ion $(50 \mu \mathrm{g})$ in each compounds was recovered as $\mathrm{AgCl}$ and converted to $\mathrm{CsCl}$ (recovery yield: 88 to $96 \%$, average: $93 \%$ ). The range of $\delta^{37} \mathrm{Cl}$ in the inorganic compounds, including $\mathrm{CsCl}$, was -2.5 to $+0.9 \%$ (Tables 4-6). Difference in raw materials, processing of salts and production of $\mathrm{Cl}_{2}$ and $\mathrm{HCl}$ gas would cause differences of $\delta^{37} \mathrm{Cl}$ in inorganic compounds.

Main resources of $\mathrm{Cl}$ are seawater, brine and 
Table 6. Measured $\delta^{37} \mathrm{Cl}$ values of the inorganic compounds

\begin{tabular}{ccccc}
\hline Run & $\mathrm{HCl}($ gas $)$ & $\mathrm{HCl}$ & $\mathrm{NaCl}$ & $\mathrm{KCl}$ \\
& $\delta^{37} \mathrm{Cl}(\% \circ)$ & $\delta^{37} \mathrm{Cl}(\% \circ)$ & $\delta^{37} \mathrm{Cl}(\% \circ)$ & $\delta^{37} \mathrm{Cl}(\% \circ)$ \\
\hline 1 & $0.88 \pm 0.14$ & $-0.26 \pm 0.33$ & $-0.95 \pm 0.34$ & $-2.30 \pm 0.31$ \\
2 & $1.03 \pm 0.28$ & $-0.24 \pm 0.32$ & $-1.04 \pm 0.28$ & $-2.26 \pm 0.32$ \\
3 & $0.85 \pm 0.16$ & $-0.22 \pm 0.25$ & $-0.96 \pm 0.47$ & $-2.16 \pm 0.37$ \\
4 & & $0.05 \pm 0.18$ & $-0.70 \pm 0.31$ & \\
& & & & \\
average & $0.92 \pm 0.10\left(1 \sigma_{\mathrm{SD}}\right)$ & $-0.17 \pm 0.15\left(1 \sigma_{\mathrm{SD}}\right)$ & $-0.91 \pm 0.15\left(1 \sigma_{\mathrm{SD}}\right)$ & $-2.24 \pm 0.07\left(1 \sigma_{\mathrm{SD}}\right)$ \\
\hline
\end{tabular}

Error for the individual runs is $2 \sigma_{m}\left(\sigma_{m}:\right.$ standard error).

evaporites. Chlorine isotopic composition in seawater is homogeneous $\left(\delta^{37} \mathrm{Cl}: 0 \%\right.$ ), and the variations in brine and halite is small (in most of the case $\delta^{37} \mathrm{Cl}:-1$ to $+1 \%$ o, Eggenkamp et al., 1995; Liu et al., 1997). Difference in raw materials would not be enough to explain the variation.

Crystallization of salts for purification from the raw materials and electrolysis for production of $\mathrm{Cl}_{2}$ gas, the most important intermediate of chlorine industry may be the steps that cause the isotopic variation in manufacturing process of inorganic and organic chlorine compounds (Eggenkamp et al., 1995; Johnston and Hutchinson, 1942; Madorsky and Straus, 1947).

\section{Chlorinated organic compounds}

The sodium biphenyl reagent, known as a reactive reductant, is used for complete extraction and qualification of organic chlorine in industrial waste. Although yield of reductive dechlorination from $c a .1 \mathrm{mg}$ of chlorinated organic solvents was high (96 to 99\%, average: $98 \%$ ), yield of $\mathrm{Cl}$ recovery as $\mathrm{CsCl}(78$ to $97 \%$, average: $85 \%$ ) was lower than the yield of $\mathrm{CuO}$-oxidation methods for $\mathrm{CH}_{3} \mathrm{Cl}$ preparation (Holt et al., 1997; Jendrzejewski et al., 1997). Since isotopic fractionation in the procedure of $\mathrm{CsCl}$ preparation from $\mathrm{Cl}^{-}$is negligible (Table 4), low recovery yield of the step would not be a problem during the analysis. Chloride ion was not detectable by ion chromatography through blank test of the pretreatment procedure. Possible contamination in the $\mathrm{CsCl}$ preparation step was less than $0.05 \%$ of $\mathrm{Cl}^{-}$ from organic compounds.
Five kinds of chlorinated aliphatic hydrocarbons were used for isotopic measurements, and the results were shown in Table 7. The variation of isotopic compositions ( -5 to $+3 \%$ ) was consistent with reported values, e.g., -6.8 to +2.6 (Tanaka and Rye, 1991), -2.9 to +4.1 (van Warmerdam et al., 1995), -2.9 to +2.1 (Holt et al., 1997), +1.0 to +3.9 (Jendrzejewski et al., 1997). The chlorinated organic solvents are formed by addition of $\mathrm{Cl}_{2}$ or $\mathrm{HCl}$ to carbon of $\mathrm{CH}_{4}$, $\mathrm{CH}_{3} \mathrm{OH}, \mathrm{C}_{2} \mathrm{H}_{4}, \mathrm{C}_{2} \mathrm{H}_{2}, \mathrm{C}_{3} \mathrm{H}_{8}$ (Grayson, 1985). Chlorine kinetic isotope effects $\left(\mathrm{k}_{35} / \mathrm{k}_{37}\right)$ on nucleophilic substitution by $\mathrm{S}_{\mathrm{N}} 1$ and $\mathrm{S}_{\mathrm{N}} 2$ reaction mechanisms showed that ${ }^{37} \mathrm{Cl}$ is bound more firmly to the carbon atom than ${ }^{35} \mathrm{Cl}$ (Turnquist et al., 1973). Therefore isotopic fractionation during the synthesis of chlorinated compounds would have a cumulative effect on isotopic variations of $\mathrm{Cl}_{2}$ and $\mathrm{HCl}$. More information on the manufacturing processes of the chlorinated organic compounds is necessary to qualify fractionation effects.

\section{Comparison of mass spectrometric methods}

Negative thermal ionization mass spectrometry (N-TIMS) of $\mathrm{Cl}^{-}$from $\mathrm{AgCl}$ was developed by Shields et al. (1962). Vengosh et al. (1989) reported a simple procedure of N-TIMS using directly loaded geochemical samples. However, these techniques based on N-TIMS of $\mathrm{Cl}^{-}$have high discrimination factor and large filament blank (Magenheim et al., 1994). Their high sensitivity is suitable for $\mathrm{Cl}$ qualification by isotope dilution mass spectrometry (Heumann et al., 1987; 
Table 7. Measured $\delta^{37} \mathrm{Cl}$ values of the chlorinated organic solvents

\begin{tabular}{cccccc}
\hline Run & $\begin{array}{c}\text { Tetrachloromethane } \\
\delta^{37} \mathrm{Cl}(\%)\end{array}$ & $\begin{array}{c}1,1,1-\text { Trichloroethane } \\
\delta^{37} \mathrm{Cl}(\%)\end{array}$ & $\begin{array}{c}1,1-\text { Dichloroethene } \\
\delta^{37} \mathrm{Cl}(\%)\end{array}$ & $\begin{array}{c}\text { Trichloroethene } \\
\delta^{37} \mathrm{Cl}(\%)\end{array}$ & $\begin{array}{c}\text { Tetrachloroethene } \\
\delta^{37} \mathrm{Cl}(\%)\end{array}$ \\
\hline 1 & $-0.22 \pm 0.16$ & $-4.89 \pm 0.33$ & $2.93 \pm 0.15$ & $-1.76 \pm 0.16$ & $-1.74 \pm 0.17$ \\
2 & $-0.20 \pm 0.19$ & $-4.94 \pm 0.25$ & $3.20 \pm 0.29$ & $-1.80 \pm 0.18$ & $-1.50 \pm 0.19$ \\
3 & $-0.79 \pm 0.35$ & $-5.20 \pm 0.30$ & $2.41 \pm 0.25$ & $-1.55 \pm 0.23$ & $-1.96 \pm 0.30$ \\
4 & $-0.10 \pm 0.20$ & & & $-1.72 \pm 0.23$ & $-2.35 \pm 0.27$ \\
5 & & & & $-1.79 \pm 0.27$ & $-1.89 \pm 0.36\left(1 \sigma_{\mathrm{SD}}\right)$ \\
\hline
\end{tabular}

Error for the individual runs is $2 \sigma_{m}\left(\sigma_{m}\right.$ : standard error).

Shinonaga et al., 1994), but they are not precise enough (uncertainty: $2 \%$ ) for isotopic analysis of most geochemical samples. This study showed that TIMS of $\mathrm{Cs}_{2} \mathrm{Cl}^{+}$was sensitive and precise enough for some purpose.

Xiao et al. loaded $\mathrm{CsCl}$ solution after loading of graphite on the filaments, and Magenheim's procedure was opposite. In the former case, graphite repels aqueous solution. In the latter case, ethanol easily spread on the filaments. In order to load the samples and graphite as small and homogeneous spot on the $\mathrm{Ta}$ filament, $\mathrm{CsCl}$ solution and graphite slurry were mixed before loading. Coarse graphite powder gave high ion current, but the mixture of $\mathrm{CsCl}$ and graphite was fragile and easily dropped from filaments. In order to prevent dropping, graphite powder was crushed with an alumina mortar. Use of wider filaments $(1.5 \mathrm{~mm}$ width) gave slightly high ion current and easier control of filament current.

The ion current intensity obtained in this study (2-3 $\times 10^{-13}$ A, $2 \mu$ g-Cl loaded) was much lower than the intensity reported by Xiao et al. (1995) $\left(7 \times 10^{-12} \mathrm{~A}, 10 \mu \mathrm{g}-\mathrm{Cl}\right.$ loaded $)$, but higher than the value reported by Magenheim et al. (1994) $\left(4 \times 10^{-14} \mathrm{~A}, 2 \mu \mathrm{g}-\mathrm{Cl}\right.$ loaded). The $\mathrm{Cl}$ isotopic ratio of seawater measured in this study was $0.319794 \pm 0.000051$ (average of run 1-25 \pm $\left.1 \sigma_{\mathrm{SD}}\right)$. This value is significantly higher than the one obtained by Xiao et al. (1995) (0.318988 \pm 0.000049: $\left.1 \sigma_{\mathrm{SD}}\right)$, but similar to the ones reported by Magenheim et al. (1994) (0.31944 \pm 0.00009 or $\left.0.31970 \pm 0.00008: 1 \sigma_{\mathrm{SD}}\right)$. As many parameters (e.g., amount of $\mathrm{Cl}$, graphite species, $\mathrm{Cl} /$ graphite ratio, $\mathrm{pH}$ of sample solution, impurities) affect the mass spectrometry of $\mathrm{Cs}_{2} \mathrm{Cl}^{+}$(Magenheim et al., 1994; Xiao et al., 1995, 2000; Banks et al., 2000; Rosenbaum et al., 2000), the main reason of the differences of ion current and isotopic ratio is not clear. The modifications of loading conditions and the use of the multi-Faraday cup mode employed in this work yielded precision better than or comparable $(0.16 \%$ ) to the level previously reported (0.15\% using $10 \mu \mathrm{g}$ of $\mathrm{Cl}$ : Xiao et al., 1995; $0.25 \%$ o using $2 \mu \mathrm{g}$ of $\mathrm{Cl}$ : Magenheim et al., 1994) using a smaller sample size $(2 \mu \mathrm{g}$ of $\mathrm{Cl})$.

Impurities or degradation products of some chlorinated organic solvent inhibited ionization of $\mathrm{CsCl}$ without activated charcoal treatment. Also, trace amount of impurity affected ionization of $\mathrm{CsCl}$ regent, this effect would be more serious for organic compounds (external reproducibility: inorganic $\mathrm{Cl}, 0.1$ to $0.2 \%$; organic $\mathrm{Cl}, 0.1$ to $0.4 \%$ o). Although the precision of the measurements $(0.10$ to $0.40 \%$ : external reproducibility, $1 \sigma_{\mathrm{SD}}$ ) was slightly lower compared to electron impact ionization mass spectrometry of $\mathrm{CH}_{3} \mathrm{Cl}(0.07 \%$ : Holt et al., 1997; 0.04 to 0.32\%o: Jendrzejewski et al., 1997), vacuum lines and furnaces are not necessary for the sodium biphenyl degradation procedure. Also, the mass spectrometry of $\mathrm{CsCl}$ requires smaller amounts of sample as chloride ion $(50 \mu \mathrm{g})$, and it is possible that the organic chlorine sample quantity for the measurements could be reduced further. 


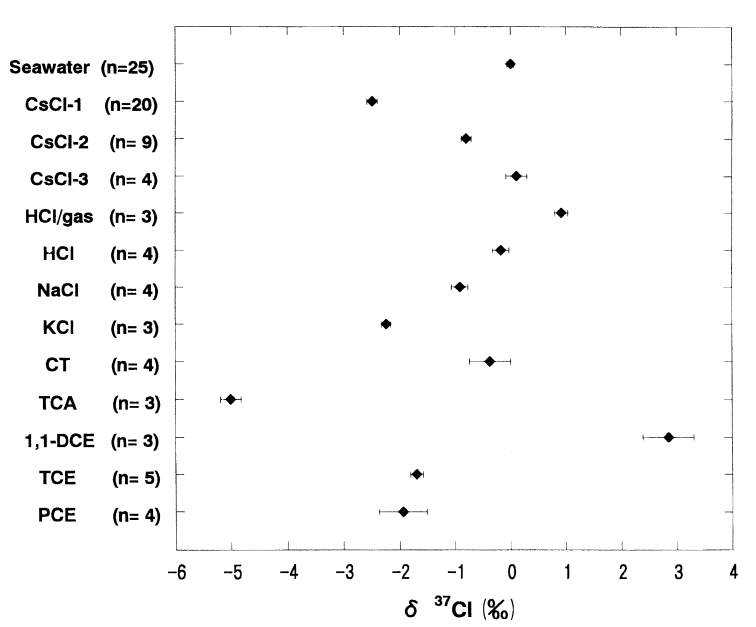

Fig. 4. Results of chlorine isotopic measurements of seawater, inorganic reagents, and chlorinated organic solvents. CsCl reagents were purchased from three companies (Nacalai tesque, Aldrich, Wako Pure Chemicals). CT: tetrachloromethane (carbon tetrachloride), TCA: 1,1,1-trichloroethane, 1,1-DCE: 1,1-dichloroethene, TCE: trichloroethene, PCE: tetrachloroethene. Error bars are $2 \sigma_{m}\left(\sigma_{m}\right.$ : external standard error).

\section{Conclusions}

Thermal ionization mass spectrometry of $\mathrm{Cs}_{2} \mathrm{Cl}^{+}$was applied for chlorine isotopic measurements of inorganic and organic chlorine compounds. Representative results in this study are shown in Fig. 4. The $\delta^{37} \mathrm{Cl}$ range of inorganic samples $(-2.5$ to $+0.9 \%$ o $)$ was similar to the range of that of most $\mathrm{Cl}$ in surface and subsurface water. On the other hand, the range of $\delta^{37} \mathrm{Cl}$ in organic compounds $(-5.0$ to $+2.9 \%$ ) was almost twice as large.

The precision (external reproducibility) of the analytical method $\left(0.1\right.$ to $0.4 \%$ : $\left.1 \sigma_{\mathrm{SD}}\right)$ was not better than the precision of the mass spectrometry of $\mathrm{CH}_{3} \mathrm{Cl}$, but was precise enough to distinguish $\mathrm{Cl}$ isotopic composition of chlorine compounds. In order to reduce the error of the method, improvement of sample preparation and loading procedure are necessary because many factors affect $\mathrm{CsCl}$ ionization process. Since it was possible to reveal $\mathrm{Cl}$ isotopic fractionation in most of the reagents and perhaps natural materials using small amounts of samples and without expensive equipment for pretreatment, this analytical procedure could be applied to solve geochemical, cosmochemical and environmental issues.

No variations in isotopic composition of seawater sample and commercial grade $\mathrm{CsCl}$ reagent from the corresponding average values were observed during the period of this study (more than 7 months). Thus, $\mathrm{CsCl}$ reagent can be used as laboratory reference standard.

Acknowledgments-We thank late Dr. Mitsunobu Tatsumoto (U.S. Geological Survey) for kindly providing us the high purity graphite. Mr. Nobuyuki Kanazawa (ThermoQuest Co. Ltd.) is thanked for his advice on measurements using MAT262 mass spectrometers. Assistance to treatments of chlorinated organic compounds by Prof. Yutaka Terashima (Graduate School of Engineering, Kyoto University) is highly acknowledged. Mr. Gabor Kondorosi (Graduate School of Science and Technology, Kobe University) for critical readings of the manuscript. We thank Dr. Ying-Kai Xiao (Qinghai Institute of Salt Lakes, China) and an anonymous reviewer for helpful comments on the manuscript. This research was supported by Grant-in-Aid (No. 11640489) from the Ministry of Education, Science, Sports and Culture of Japan.

\section{REFERENCES}

Banks, D. A., Green, R., Cliff, R. A. and Yardley, B. W. D. (2000) Chlorine isotopes in fluid inclusions: Determination of the origins of salinity in magmatic fluid. Geochim. Cosmochim. Acta 64, 1785-1789.

Boudreau, A. E., Stewart, M. A. and Spivack, A. J. (1997) Stable Cl isotopes and origin of high-Cl magmas of the Stillwater Complex, Montana. Geology 25, 791-794.

Boyd, A. W., Brown, F. and Lounsbury, M. (1955) Mass spectrometric study of natural and neutron-irradiated chlorine. Can. J. Phys. 33, 35-42.

Desaulniers, D. E., Kaufmann, R. S., Cherry, J. A. and Bentley, H. W. $(1986){ }^{37} \mathrm{Cl}-{ }^{35} \mathrm{Cl}$ variations in a diffusion-controlled groundwater system. Geochim. Cosmochim. Acta 50, 1757-1764.

Eastoe, C. J. and Guilbert, J. M. (1992) Stable chlorine isotopes in hydrothermal processes. Geochim. Cosmochim. Acta 56, 4247-4255.

Eggenkamp, H. G. M. and Koster van Groos, A. F. (1997) Chlorine stable isotopes in carbonatites: evidence for isotopic heterogeneity in the mantle. Chem. Geol. 140, 137-143. 
Eggenkamp, H. G. M., Middelburg, J. J. and Kreulen, R. (1994) Preferential diffusion of ${ }^{35} \mathrm{Cl}$ relative to ${ }^{37} \mathrm{Cl}$ in sediments of Kau Bay, Halmahera, Indonesia. Chem. Geol. (Isotope Geosci. Sect.) 116, 317325.

Eggenkamp, H. G. M., Kreulen, R. and Koster van Groos, A. F. (1995) Chlorine stable isotope fractionation in evaporite. Geochim. Cosmochim. Acta 59, 5169-5175.

Grayson, M. (ed.) (1985) Kirk-Othmer Concise Encyclopedia of Chemical Technology. John Wiley \& Sons, New York.

Heumann, K. G., Gall, M. and Weiss, H. (1987) Geochemical investigations to explain iodineoverabundances in Antarctic meteorites. Geochim. Cosmochim. Acta 51, 2541-2547.

Hoefs, J. (1997) Stable Isotope Geochemistry. SpringerVerlag, Berlin, pp. 62-63.

Hoering, T. C. and Parker, P. L. (1961) The geochemistry of the stable isotopes of chlorine. Geochim. Cosmochim. Acta 23, 186-199.

Holt, B. D., Sturchio, N. C., Abrajano, T. A. and Heraty, L. J. (1997) Conversion of chlorinated volatile organic compounds to carbon dioxide and methyl chloride for isotopic analysis of carbon and chlorine. Anal. Chem. 69, 2727-2733.

Jendrzejewski, N., Eggenkamp, H. G. M. and Coleman, M. L. (1997) Sequential determination of chlorine and carbon isotopic composition in single microliter samples of chlorinated solvent. Anal. Chem. 69, 4259-4266.

Johnston, H. L. and Hutchison, D. A. (1942) Efficiency of the electrolytic separation of chlorine isotopes. $J$. Chem. Phys. 10, 469-472.

Kaufmann, R. S., Long, A., Bentley, H. and Davis, S. (1984) Natural chlorine isotope variations. Nature 309, 338-340.

Kaufmann, R. S., Frape, S. K., McNutt, R. and Eastoe, C. (1993) Chlorine stable isotope distribution of Michigan Basin formation waters. Appl. Geochem. 8, 403-407.

Liggett, L. M. (1954) Determination of organic halogen with sodium biphenyl reagent. Anal. Chem. 26, 748-750.

Liu, W. G., Xiao, Y. K., Wang, Q. Z., Qi, H. P., Wang, Y. H., Zhou, Y. M. and Shirodkar, P. V. (1997) Chlorine isotopic geochemistry of salt lakes in the Qaidam Basin, China. Chem. Geol. 136, 271-279.

Long, A., Eastoe, C. J., Kaufmann, R. S., Martin, J. G., Wirt, L. and Finley, J. B. (1993) High-precision measurement of chlorine stable isotope ratios. Geochim. Cosmochim. Acta 57, 2907-2912.

Lyons, W. B., Frape, S. K. and Welch, K. A. (1999) History of McMurdo Dry Valley lakes, Antarctica, from stable chlorine isotope data. Geology 27, 527530 .

Madorsky, S. L. and Straus, S. (1947) Concentration of isotopes of chlorine by the counter-current electromigration method. J. Res. Natl. Bur. Stand. 38, 185-189.

Magenheim, A. J., Spivack, A. J., Volpe, C. and Ransom, B. (1994) Precise determination of stable chlorine isotopic ratios in low-concentration natural samples. Geochim. Cosmochim. Acta 58, 3117-3121.

Magenheim, A. J., Spivack, A. J., Michael, P. J. and Gieskes, J. M. (1995) Chlorine stable isotope composition of the oceanic crust: Implications for earth's distribution of chlorine. Earth Planet. Sci. Lett. 131, 427-432.

Markl, G., Musashi, M. and Bucher, K. (1997) Chlorine stable isotope composition of granulites from Loften, Norway: Implications for the $\mathrm{Cl}$ isotopic composition and for the source of $\mathrm{Cl}$ enrichment in the lower crust. Earth Planet. Sci. Lett. 150, 95-102.

Musashi, M., Markl, G. and Kreulen, R. (1998) Stable chlorine-isotope analysis of rock samples: New aspects of chlorine extraction. Anal. Chim. Acta 362, 261-269.

Phillips, F. M. (1995) The use of isotopes and environmental tracers in subsurface hydrology. Rev. Geophys. Supplement, 1029-1033.

Phillips, F. M. and Bentley, H. W. (1987) Isotopic fractionation during ion filtration: I. Theory. Geochim. Cosmochim. Acta 51, 683-695.

Ransom, B., Spivack, A. J. and Kastner, M. (1995) Stable $\mathrm{Cl}$ isotopes in subduction-zone pore waters: Implications for fluid-rock reactions and the cycling of chlorine. Geology 23, 715-718.

Rosenbaum, J. M., Cliff, R. A. and Coleman, M. L. (2000) Chlorine stable isotopes; A comparison of dual inlet and thermal ionization mass spectrometric measurements. Anal. Chem. 72, 2261-2264.

Shields, W. R., Murphy, T. J., Garner, E. L. and Dibeler, V. H. (1962) Absolute isotopic abundance ratio and the atomic weight of chlorine. J. Am. Chem. Soc. 84, 1519-1522.

Shinonaga, T., Ebihara, M., Nakahara, H., Tomura, K. and Heumann, K. G. (1994) $\mathrm{Cl}, \mathrm{Br}$ and $\mathrm{I}$ in igneous standard rocks. Chem. Geol. 115, 213-225.

Sturchio, N. C., Clausen, J. L., Heraty, L. J., Huang, L., Holt, B. D. and Abrajano, T. A., Jr. (1998) Chlorine isotope investigation of natural attenuation of trichloroethene in an aerobic aquifer. Environ. Sci. Technol. 32, 3037-3042.

Tanaka, N. and Rye, D. M. (1991) Chlorine in the stratosphere. Nature 353, 707.

Taylor, J. W. and Grimsrud, E. P. (1969) Chlorine isotopic ratios by negative ion mass spectrometry. Anal. 
Chem. 41, 805-810.

Turnquist, C. R., Taylor, J. W., Grimsrud, E. P. and Williams, R. C. (1973) Temperature dependence of chlorine kinetic isotope effects for aliphatic chlorides. J. Am. Chem. Soc. 95, 4133-4138.

van Warmerdam, E. M., Frape, S. K., Aravena, R., Drimmie, R. J., Flatt, H. and Cherry, J. A. (1995) Stable chlorine and carbon isotope measurements of selected chlorinated organic solvents. Appl. Geochem. 10, 547-552.

Vengosh, A. Chivas, A. R. and McCulloch, M. T. (1989) Direct determination of boron and chlorine isotopic compositions in geological materials by negative thermal-ionization mass spectrometry. Chem. Geol. (Isotope Geosci. Sect.) 79, 333-343.

Volpe, C. and Spivack, A. J. (1994) Stable chlorine isotopic composition of marine aerosol particles in the western Atlantic Ocean. Geophys. Res. Lett. 21, 1161-1164.

Volpe, C., Wahlen, M., Pszenny, A. A. P. and Spivack, A. J. (1998) Chlorine isotopic composition of ma- rine aerosols: Implications for the release of reactive chlorine and $\mathrm{HCl}$ cycling rates. Geophys. Res. Lett. 25, 3831-3834.

Wastaway, K. C., Koemer, T., Fang, Y. R., Rudziñski, J. and Paneth, P. (1998) A new method of determining chlorine kinetic isotope effect. Anal. Chem. 70, 3548-3552.

Xiao, Y. K. and Zhang, C. G. (1992) High precision isotopic measurement of chlorine by thermal ionization mass spectrometry of the $\mathrm{Cs}_{2} \mathrm{Cl}^{+}$ion. Int. J. Mass Spectrom. Ion Proc. 116, 183-192.

Xiao, Y. K., Zhou, Y. M. and Liu, W. G. (1995) Precise measurement of chlorine isotopes based on $\mathrm{Cs}_{2} \mathrm{Cl}^{+}$ by thermal ionization mass spectrometry. Anal. Lett. 28, 1295-1304.

Xiao, Y. K., Wei, H. Z., Zhou, Y. M., Wang, Y. H. and Liu, W. G. (2000) Investigation of characteristics of non-reductive thermal ion emission of various graphites in thermal ionization mass spectrometry. Anal. Chim. Acta 420, 95-101. 